\title{
Pengaruh Kondisi Vasektomi pada Perilaku Reproduksi Monyet Ekor Panjang (Macaca fascicularis) di Yayasan Inisiasi Alam Rehabilitasi Indonesia, Bogor
}

\author{
Hana Nabilah ${ }^{1}$, Luthfiralda Sjahfirdi ${ }^{2}$, Wendi Prameswari ${ }^{3}$ \\ ${ }^{1,2}$ Departemen Biologi, Fakultas Matematika dan Ilmu Pengetahuan Alam Universitas Indonesia, \\ Gedung E FMIPA, Depok 16424. Republik Indonesia \\ ${ }^{3}$ Yayasan Inisiasi Alam Rehabilitasi Indonesia, Bogor. Jl. Curug Nangka Kp. Sinarwangi, Ciapus \\ Tamansari, Bogor, 16610. Republik Indonesia
}

Penulis untuk Korespondensi/E-mail: luthfiralda@gmail.com

\begin{abstract}
Abstrak - Telah dilakukan pengamatan perilaku reproduksi moyet ekor panjang (Macaca fascicularis) di Yayasan Inisiasi Alam Rehabilitasi Indonesia (YIARI) yang telah disterilkan dengan metode vasektomi. Tujuan penelitian adalah mengamati pengaruh vasektomi monyet ekor panjang terhadap perilaku reproduksinya. Pengamatan dilakukan pada tiga ekor monyet ekor panjang jantan (Jantan1, Jantan2, dan Jantan3) yang dikandangkan bersama dua ekor monyet ekor panjang betina (Betina1 dan Betina2) dengan metode scan sampling dan ad libitum dengan interval waktu 5 menit tanpa jeda. Pengamatan dilakukan dari pukul 08.00-15.00 WIB selama 14 hari di bulan Agustus 2016, serta dengan total titik sampel yang diperoleh adalah 1008. Hasil pengamatan menunjukkan ketiga jantan masih aktif melakukan perilaku reproduksi, dengan Jantan1 yang merupakan jantan dominan dalam kelompok yang lebih mendominasi betina dibanding Jantan2 dan Jantan3, dibuktikan dengan nilai MM (Male Mounts) terhadap betina yaitu Jantan1 sebanyak 111 kali, Jantan2 sebanyak 10 kali dan Jantan3 sebanyak 21 kali. Perilaku reproduksi pada ketiga jantan masih ditemukan karena metode vasektomi tidak merusak proses spermatogenesis sehingga sistem hormonal hewan tidak terganggu. Terdapat perbedaan frekuensi perilaku reproduksi jantan terhadap Betina1 dan Betina2. Hal tersebut dikarenakan preferensi jantan dalam kelompok yang lebih memilih untuk kawin dengan Betina1 daripada Betina2, yang dibuktikan dengan nilai FRS (Female Refuses Sex) dari Betina1 terhadap jantan sebanyak 111 kali sementara Betina2 sebanyak 7 kali. Diduga Betina1 merupakan betina dominan dengan kadar hormon estrogen yang lebih tinggi daripada Betina2.
\end{abstract}

Kata Kunci - Macaca fascicularis, Rehabilitasi, Perilaku Reproduksi, Vasektomi

Abstract - A study of reproductive behavior has been conducted on long tail macaques (Macaca fascicularis) which have been sterilized by a vasectomy method at Yayasan Inisiasi Alam Rehabilitasi Indonesia (YIARI), Bogor. The purpose of the study is to observe the influence of vasectomy to reproductive behavior of those animals. Observation was conducted on 3 (three) male macaques (the code names are: Jantan1, Jantan2 and Jantan3) which were captive-housed with 2 other female macaques (the code names are: Betina1 and Betina2). The method of observation is a combination of scan sampling and ad libitum methods with 5 (five) minutes intervals without pause. Daily observation were done from 08:00 am to 03:00 pm for 14 days in August 2016 and brought about 1,008 sample points. Results showed all males still actively performed reproductive behavior with Jantan1 in dominant position to all females compared to other males. Male Mounts (MM) of Jantan1 (111 times) was found higher than other males (Jantan2 10 times and Jantan3 21 times). We resume that reproductive behavior was still found 
in all males because vasectomy methods did not affect spermatogenesis process therefore the hormonal system remain in normal condition. There are differences in the frequency of males' reproductive behavior to all females since all males preferring to mate with Betina1 instead of Betina2. The Female Refuse Sex behavior to males was found higher in Betina1 (111 times) than Betina2 (7 times) as Betina1 assumed to be dominant than Betina2.

Keywords - Macaca fascicularis, Rehabilitation, Reproductive Behavior, Vasectomy

\section{PENDAHULUAN}

$M$ acaca fascicularis atau monyet ekor panjang (nama lainnya adalah long tailed macaque, crab-eating monkey dan cynomolgus monkey) merupakan primata yang memiliki panjang ekor hampir sama dengan panjang tubuhnya. Tingkat adaptasi monyet ekor panjang tinggi, sehingga dapat hidup di habitat yang beragam mulai dari hutan rawa, hutan sekunder, daerah aliran sungai, serta hutan mangrove. Distribusi monyet ekor panjang tersebar secara acak di wilayah Asia Tenggara seperti di Indonesia, Thailand, serta Malaysia (Saputra dkk. 2015: 7). Karena distribusinya yang luas di Asia Tenggara, status monyet ekor panjang ditetapkan sebagai least concern oleh IUCN (IUCN 2016: 1). Di Indonesia, Monyet ekor panjang tersebar di beberapa daerah seperti Pulau Sumatera, Kalimantan, Jawa, Bali, serta kepulauan NTT.

Di alam, monyet ekor panjang hidup berkelompok dengan sistem multimale dan multifemale. Sistem reproduksi monyet ekor panjang adalah polygyny, yaitu jantan maupun betina secara umum dapat mempunyai lebih dari satu pasangan. Kesuksesan reproduksi monyet ekor panjang bergantung pada hirarki, yaitu alpha male dalam kelompok lebih dominan dalam melakukan perilaku reproduksi atau perilaku seksual, kondisi fisik monyet ekor panjang, serta bergantung dari faktor lingkungan seperti ketersediaan pakan (Anuar 2010: 23).

Habitat monyet ekor panjang seringkali tumpang tindih dengan pemukiman masyarakat sehingga tak jarang menimbulkan konflik. Selain itu, masalah lain terkait dengan keberadaan monyet ekor panjang di Indonesia yaitu primata ini banyak dijual dan disalahgunakan untuk berbagai tujuan, serta karena tingkat adaptasinya yang tinggi, memperbesar kemungkinan menjadi spesies invasif di daerah tertentu (Kemp \& Burnett
2003: 12). Berbagai permasalahan yang ada mengindikasikan perlunya peran lembaga konservasi untuk melindungi monyet ekor panjang, salah satunya yaitu Yayasan Inisiasi Alam Rehabilitasi Indonesia (YIARI).

Yayasan Rehabilitasi Satwa International Animal Rescue merupakan sebuah organisasi sosial yang didirikan di Inggris pada tahun 1988 dan kini telah berdiri di Amerika, India, Malta, dan Indonesia. Tujuan International Animal Rescue antara lain penyelamatan dan rehabilitasi hewan-hewan liar dan hewanhewan domestik yang terlantar, mengembalikan hewan-hewan yang telah diselamatkan ke habitat alami, serta menyediakan tempat perlindungan untuk hewan-hewan yang memungkinkan untuk dikembalikan ke habitat alaminya. Monyet ekor panjang menjadi salah satu objek penyelamatan dan rehabilitasi di International Animal Rescue Indonesia, atau Yayasan Inisasi Alam Rehabilitasi Indonesia (YIARI) (IAR Indonesia 2010:3).

Kondisi monyet ekor panjang di yayasan rehabilitasi tentunya berbeda dengan kondisi yang hidup di alam liar. Salah satu kondisi yang membedakan adalah tidak diperbolehkannya aktivitas breeding atau bereproduksi. Aktivitas breeding tidak diperkenankan karena jika dihasilkan anak di yayasan rehabilitasi dikhawatirkan tidak dapat beradaptasi di habitat alami jika dilepasliarkan. Untuk menunjang tidak dihasilkannya anak di yayasan rehabilitasi, maka monyet ekor panjang yang berada di YIARI disterilkan dengan menggunakan 2 (dua) metode yaitu metode kastrasi (castration) dan vasektomi (vasectomy).

Kastrasi merupakan metode sterilisasi pada jantan dengan pengambilan testis dari tubuh hewan jantan, baik dengan tindakan bedah maupun menggunakan bahan kimia (Phoenix 1973: 1045). Vasektomi merupakan metode yang mengikat saluran vas deferens untuk 
mencegah spermatozoa keluar dari traktus reproduksi jantan (Peng dkk. 2002: 847). Kedua metode tersebut diyakini dapat mempengaruhi perilaku reproduksinya, dan juga diyakini dapat menimbulkan perilaku lain yang menyertai perilaku reproduksi tersebut. Sejauh ini belum diketahui secara pasti apakah metode steril pada jantan ada pengaruh terhadap perilaku reproduksinya.

\section{Tujuan}

Penelitian ini merupakan studi awal yang bertujuan untuk mengetahui beberapa hal yang nantinya dapat dimanfaatkan oleh manajemen YIARI dalam menunjang keberhasilan yayasan rehabilitasi. Hal-hal yang menjadi tujuan penelitian ini adalah 1). Mengamati ada tidaknya pengaruh vasektomi terhadap kemunculan perilaku reproduksi monyet ekor panjang jantan; 2) mengamati interaksi reproduktif monyet ekor panjang jantan yang sudah dalam kondisi tervasektomi terhadap keberadaan betina yang dikandangkan bersama; 3). Mencermati perilaku lain yang menyertai perilaku reproduksi tersebut.

\section{Manfaat}

Penelitian mengenai pengaruh kondisi vasektomi terhadap perilaku reproduksi monyet ekor panjang diperlukan mengingat kondisi monyet ekor panjang di yayasan rehabilitasi yang berbeda dengan monyet ekor panjang di habitat alami, sehingga kemungkinan terdapat perbedaan perilaku di antara keduanya. Selain itu, hasil studi awal dapat dijadikan sebagai bahan referensi atau rujukan oleh pihak pengelola Yayasan Inisiasi Alam Rehabilitasi Indonesia (YIARI) untuk peningkatan dan optimalisasi program konservasi ex situ.

\section{METODOLOGI}

\section{Lokasi dan Waktu Penelitian}

Penelitian dilakukan di Yayasan Inisiasi Alam Rehabilitasi Indonesia (YIARI), Bogor. Lokasi penelitian yaitu pada kandang monyet ekor panjang blok A dan blok B. Pengamatan dilakukan di bulan Agustus 2016.

\begin{abstract}
Alat dan Bahan
Peralatan yang digunakan ialah lembar pengamatan, alat tulis, pakaian kandang, dan alat penunjuk waktu.

Bahan yang menjadi subjek dalam penelitian ialah satu kelompok monyet ekor panjang dengan anggota tiga jantan dewasa yaitu Jantan1, Jantan2, serta Jantan3 dan dua betina dewasa yaitu Betina1 dan Betina2. Status reproduksi ketiga jantan adalah disterilkan dengan metode vasektomi pada saat telah matang kelamin pada Januari 2016. Dua ekor betina belum disterilkan, non-virgin, dan sebelumnya pernah memiliki anak. Kelima monyet ekor panjang yang menjadi objek pengamatan merupakan hewan sitaan oleh Balai Konservasi Sumber Daya Alam (BKSDA) Serang, yang berasal dari kebun binatang Cikole Air Sprite (CAS) Serang, Banten. Kondisi hewan seluruhnya dalam keadaan sehat, dengan gigi lengkap dan sudah lolos tes tuberculosis. Tidak terdapat catatan kelahiran untuk kelima hewan tesebut, namun diketahui seluruhnya dikategorikan telah matang kelamin ketika masuk yayasan rehabilitasi dan sejak berada di Cikole Air Sprite (CAS) Serang.
\end{abstract}

\section{Cara Kerja}

Pengambilan data dilakukan dengan metode scan sampling dan ad libitum dengan interval waktu 5 (lima) menit tanpa jeda. Pada metode scan sampling perilaku seluruh hewan dalam kelompok diamati dan dicatat (dalam interval waktu yang telah ditentukan) sementara metode ad libitum mencatat semua perilaku yang tampak dan terlihat relevan (Altmann 1974: 235-247).

Pengamatan dilakukan sejak tanggal $12-25$ Agustus 2016. Pengambilan data dilakukan setiap hari selama 14 hari sejak pukul 08.00 hingga 15.00 WIB dengan jeda waktu istirahat satu jam, sehingga total waktu pengamatan selama satu hari sebanyak 6 (enam) jam, sehingga dalam satu hari terdapat 72 titik sampel atau selama 360 menit. Total waktu pengambilan data yang dilakukan ialah sebanyak 1008 titik sampel atau selama 5040 menit. 
Perilaku yang diamati pada monyet ekor panjang jantan meliputi: Approaching Sex Partner (APP) atau menghampiri partner seks, Male Inspects Genitalia (MIG) atau menginspeksi organ genitalia betina, Male Mounts (MM) atau mengawini betina, serta Masturbate (MTB) atau masturbasi, sedangkan perilaku yang diamati pada monyet ekor panjang betina meliputi: Approaching Sex Partner (APP) atau menghampiri partner seks, Female Presents Genitalia (FPG) atau menunjukkan organ genitalia, serta Female Refuses Sex (FRS) atau menolak perilaku seksual.

\section{Analisis Data}

Analisis data dilakukan secara deskriptif dengan menghitung frekuensi setiap perilaku. Hasil akan dipisahkan berdasarkan jenis kelamin, lalu frekuensi perilaku antarindividu dalam kelompok dibandingkan.

\section{HASIL PENGAMATAN}

Hasil yang diperoleh berupa rerata perilaku reproduksi monyet ekor panjang jantan (Gambar 1.) dan betina (Gambar 2.) dalam frekuensi perilaku yang terjadi, dilengkapi dengan penjabaran perilaku repoduksi yang berhasil diamati

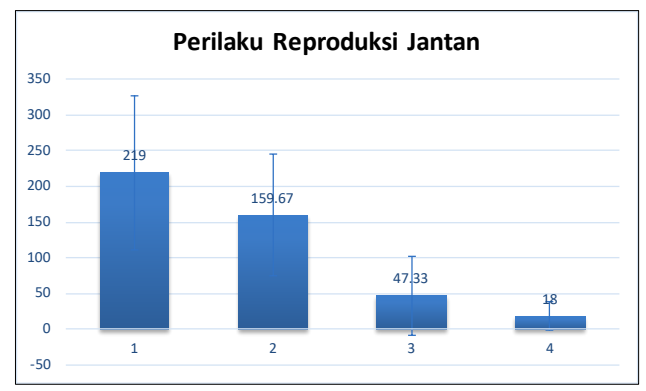

Gambar 1. Hasil pengamatan rerata frekuensi perilaku reproduksi monyet ekor panjang ketiga jantan.

Ket.: Angka 1 menunjukkan Approaching Sex Partner (APP) atau menghampiri partner seks, angka 2 menunjukkan perilaku Male Inspects Genitalia (MIG) atau menginspeksi organ genitalia betina, angka 3 menunjukkan perilaku Male Mounts (MM) atau mengawini betina, dan angka 4 menunjukkan perilaku Masturbate (MTB) atau masturbasi.

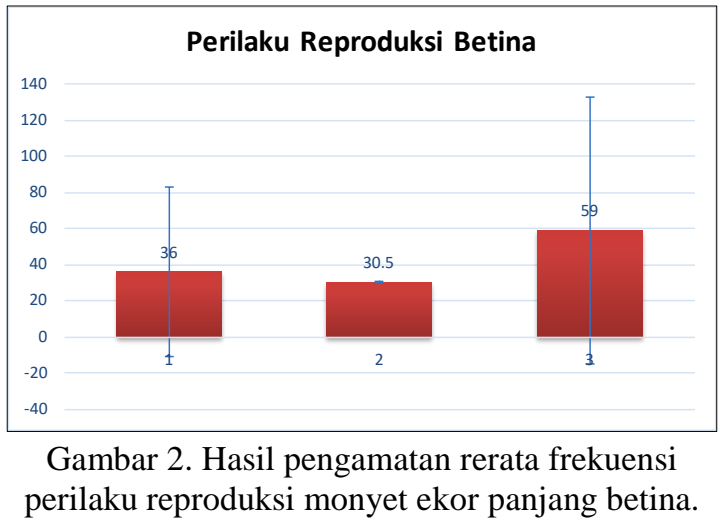

Ket: Angka 1 menunjukkan rerata perilaku Approaching Sex Partner (APP) atau menghampiri partner seks; Angka 2 menunjukkan rerata Female Presents Genitalia (FPG) atau menunjukkan organ genitalia; Angka 3 menunjukkan rerata Female Refuses Sex (FRS) atau menolak perilaku seksual.

Selama pengamatan seluruh jantan masih aktif melakukan perilaku reproduksi, yang didominasi oleh Jantan1 (Tabel 1). Ketiga jantan dalam kelompok juga menunjukkan ketertarikan yang lebih untuk melakukan aktivitas reproduksi dengan Betina1 dibandingkan dengan Betina2.

Tabel.1 Hasil pengamatan perilaku reproduksi monyet ekor panjang jantan

\begin{tabular}{lllll}
\hline Individu & $\begin{array}{l}\text { Approaching Sex } \\
\text { Partner (APP) }\end{array}$ & $\begin{array}{l}\text { Male Inspects } \\
\text { Genitalia (MIG) }\end{array}$ & $\begin{array}{l}\text { Male Mounts } \\
\text { (MM) }\end{array}$ & Masturbate (MTB) \\
\hline Jantan 1 & 340 & 255 & 111 & 40 \\
Jantan 2 & 133 & 93 & 10 & 2 \\
Jantan 3 & 184 & 131 & 21 & 12 \\
& & & & \\
\hline Rerata & 219 & 159,67 & 47,33 & 18 \\
SD & 107,85 & 84,72 & 55,41 & 19,70 \\
\hline
\end{tabular}


Meski terjadi penolakan oleh para betina, namun kemunculan penolakan betina terhadap jantan membuktikan bahwa jantan berupaya untuk menarik perhatian betina. Selama pengamatan frekuensi penolakan betina terhadap jantan ditemukan lebih tinggi pada Betina1 (111) dibanding Betina2 (7)
Frekuensi perilaku reproduksi antara Betina1 dan Betina2 menunjukkan perbandingan yang cukup besar. Pada perilaku APP atau menghampiri partner seks, dan perilaku FRS atau menolak perilaku seksual, frekuensi pada Betina1 lebih tinggi dibanding Betina2 (Tabel 2).

Tabel 2. Frekuensi perilaku reproduksi betina terhadap jantan. Perilaku reproduksi positif ditunjukkan melalui APP dan FPG, sedangkan perilaku reproduktif negatif melalui FRS.

\begin{tabular}{lccc}
\hline Individu & Approaching Sex Partner (APP) & $\begin{array}{c}\text { Female Presents } \\
\text { Genitalia (FPG) }\end{array}$ & $\begin{array}{c}\text { Female Refuses } \\
\text { Sex (FRS) }\end{array}$ \\
\hline Betina 1 & 3 & 30 & 111 \\
Betina 2 & 69 & 31 & 7 \\
& & & 59 \\
\hline Rerata & 36 & 30,5 & 73,54 \\
SD & 46,67 & 0,71 & \\
\hline
\end{tabular}

\section{PEMBAHASAN}

Dari hasil pengamatan terlihat bahwa ketiga jantan masih aktif melakukan perilaku reproduksi meski telah divasektomi. Vasektomi merupakan metode kontrasepsi pada jantan dengan jalan mengikat saluran vas deferens untuk mencegah spermatozoa keluar dari traktus reproduksi jantan. Dengan terhambatnya pengeluaran spermatozoa, bila terjadi kopulasi maka fertilisasi tidak akan terjadi karena yang masuk ke dalam traktus reproduksi betina hanya cairan semen tanpa spermatozoa (Egbetade dkk. 2014: 108).

Perilaku reproduksi pada ketiga jantan masih ditemukan karena metode vasektomi merupakan perlakuan fisik pada genitalia interna jantan, yang tidak berpengaruh terhadap sekresi hormon sehingga tidak mengganggu proses spermatogenesis atau mengurangi jumlah spermatozoa yang dibentuk dalam epididymis. Dengan demikian hewan yang disterilkan dengan metode vasektomi tidak terganggu secara hormonal (Peng dkk. 2002: 847).

Sebuah studi yang dilakukan pada monyet rhesus (Macaca mulatta) yang telah disterilkan menyimpulkan bahwa tidak terdapat perbedaan berarti pada histologi dari testis, epididimis, kelenjar prostat, serta seminal vesicle antara kelompok monyet rhesus yang disterilkan dengan kelompok kontrol, mengindikasikan bahwa vasektomi yang dilakukan tidak mempengaruhi morfologi serta fungsi organorgan tersebut (Peng dkk. 2002: 850--852).

Perilaku reproduksi yang diamati pada jantan meliputi menghampiri partner seks (APP), menginspeksi organ genitalia betina (MIG), mengawini betina (MM), serta masturbasi (MTB). Menghampiri partner seks yaitu perilaku mendekati betina hingga kurang dari 0,6 m, sedangkan inspeksi organ genitalia dan menkopulasi betina merupakan rangkaian perilaku reproduksi monyet ekor panjang yang dilakukan dengan mengangkat ekor betina kemudian menginspeksi genitalia betina dengan memasukan jari, menjilat atau mengendus vagina, dan dilanjutkan dengan menaiki betina (mounting), dan kopulasi, sesuai dengan hasil-hasil yang diperoleh Anuar (2010: 24).

Masturbasi merupakan perilaku ritmik meraba penis yang ereksi, baik dengan tangan maupun kaki yang dapat mengakibatkan ejakulasi. Perilaku masturbasi pada primata umum terjadi terutama pada spesies dengan sistem reproduksi multimale dan multifemale (Thomsen 2000: 22). Selama pengambilan data, perilaku masturbasi terjadi di awal periode observasi, saat jantan merasa tertantang dengan jantan lain, atau ketika sedang beristirahat di atas dahan. Perilaku masturbasi lebih sering terlihat dilakukan oleh Jantan1. Dalam pengambilan 
data, perilaku meraba penis yang ereksi dengan tangan maupun kaki dicatat sebagai masturbasi walau tidak sampai terjadi ejakulasi.

Selama pengamatan juga tercatat telah terjadi beberapa kali perilaku homoseksual antara Jantan1, Jantan2, dan Jantan3. Perilaku homoseksual yang terjadi berupa jantan menaiki jantan lainnya (mounting). Mounting terjadi pada Jantan1 terhadap Jantan2 dan Jantan3, dan Jantan 2 terhadap Jantan3. Menurut penelitian, perilaku homoseksual berupa mounting antarjantan tak selalu berhubungan dengan faktor reproduksi, namun juga merupakan fungsi sosial. Penelitian yang dilakukan pada Macaca nemestrina menyatakan, perilaku homoseksual lebih menjurus kepada jantan dominan dengan jantan subordinat ketika keadaan kelompok stabil dan jantan dominan diterima baik dalam kelompok. Perilaku homoseksual dianggap sebagai fenomena timbal balik jangka panjang dan bergantung dari stabilitas kelompok (Gumert 2015: 7). Dengan demikian, perilaku homoseksual yang terjadi antarjantan dominan (Jantan1) dan jantan subordinat (Jantan2 dan Jantan3) menggambarkan bahwa jantan dominan telah diterima baik oleh kelompok.

Hasil menunjukkan bahwa Jantan1 lebih mendominasi betina dalam kelompok. Hal ini dibuktikan dengan perilaku reproduksinya yang jauh lebih besar jika dibandingkan dengan Jantan2 dan Jantan3 (Tabel 1). Hal ini dikarenakan kompetisi antarjantan dalam mengawini betina pada monyet ekor panjang berdasar pada sistem sosial yang berarti jantan terkuat dapat memonopoli akses ke betina fertil.

Faktor lain yang mendukung kesuksesan reproduksi jantan yaitu kekuatan bertarung serta membentuk koalisi dengan jantan subordinat (Engelhardt dkk. 2006: 741). Individu yang dominan umumnya mendapat lebih banyak akses untuk memperoleh makanan, ruang, serta keamanan, sehingga kesuksesan reproduksi juga lebih tinggi (Noordwijk 1999: 106). Selama pengamatan, Jantan1 menunjukkan perilaku-perilaku yang mengindikasikan dirinya merupakan jantan dominan dengan hampir selalu memenangkan kompetisi terhadap dua jantan lainnya baik dalam hal memperebutkan betina maupun makanan. Jantan1 juga lebih agresif karena tercatat sering menantang jantan lain, menggerak-gerakan dahan untuk menunjukkan kekuasaan, serta mengancam dengan mengecap bibir dengan gerakan cepat (Anuar 2010: 24).

Jika dibandingkan dengan Jantan1, perilaku reproduksi Jantan2 dan Jantan3 lebih rendah (Tabel 1). Selain diindikasikan Jantan1 merupakan jantan dominan, faktor lain yang mempengaruhi perilaku reproduksi pada monyet ekor panjang yaitu ketersediaan sumber daya, nilai yang dimiliki pasangan, serta usaha jantan dalam mendapat akses kepada betina yang bergantung dari kemampuan jantan untuk menampilkan atau menunjukkan sesuatu yang dapat menarik perhatian betina (Gumert 2007:1656).

Perilaku reproduksi yang diamati pada betina yaitu menghampiri partner seks (APP), menunjukkan organ genitalia (FPG), serta menolak perilaku seksual (FRS). Betina menolak perilaku seksual dengan menjauh dari jantan yang memaksa kawin, atau dengan perilaku agonistik seperti mengancam dan menggigit. Perilaku menunjukkan organ genitalia dilakukan dengan memperlihatkan area anogenital pada jantan (Engelhardt 2005: 197). Perilaku APP dan FPG dapat dianggap perilaku reprodukstif yang bersifat positif (tidak menolak jantan) dan perilaku FRS dapat dianggap sebagai perilaku reproduktif negatif karena menolak jantan, meski ketiga perilaku yang diamati tersebut dikategorikan sebagai perilaku reproduktif betina terhadap jantan.

Seperti perilaku primata yang dijumpai pada umumnya, monyet ekor panjang betina cenderung lebih reseptif dalam menerima perilaku reproduksi dari jantan selama masa fertil atau masa subur. Jantan dapat melihat fase fertil betina dari perilaku seksual yang dilakukannya, dan lebih tertarik untuk kawin dengan betina yang sedang dalam masa fertil (Engelhard dkk. 2005: 195). Masa fertil hanya berlangsung selama beberapa hari dan jika sedang berada pada masa fertil, kopulasi yang dilakukan jantan terhadap betina akan membuahkan kehamilan.

Pada masa fertil, betina akan menunjukkan perilaku reproduktif kepada jantan, seperti memperlihatkan organ reproduksinya. Selama pengamatan, betina sering kali menunjukkan organ genitalia pada jantan (RFG). Betina1 
tercatat melakukan RFG pada hari ke-2 pengamatan sebanyak 19 kali, dan Betina2 pada hari ke-6 pengamatan sebanyak 7 kali. Selama masa tersebut, kedua betina cenderung jarang menolak jantan yang dibuktikan dengan nilai perilaku FRS yang rendah, yaitu pada Betina1 sebanyak 4 kali dan pada Betina2 tidak terjadi penolakan sama sekali (Tabel 2.)

Pengamatan perilaku reproduksi betina memperlihatkan perbedaan antara perilaku APP dan FRS pada Betina1 dibanding pada Betina2. Frekuensi perilaku APP lebih banyak pada Betina2 (69 kali) dibanding pada Betina1 (3 kali). Nilai FRS Betina1 lebih tinggi (111 kali) dibanding pada Betina2 (7 kali). Selama pengamatan, ketiga jantan dalam kelompok jauh lebih sering berkopulasi dan mencoba berkopulasi dengan Betina1 dibandingkan dengan Betina2, yang dibuktikan dengan frekuensi perilaku FRS Betina1 yang jauh lebih tinggi daripada Betina2. Meski demikian, Betina2 tercatat lebih sering mendekati jantan (APP) untuk grooming, sementara pada Betina1, jantan akan mendekatinya terlebih dahulu untuk meminta grooming, sehingga Betina1 jarang tercatat mendekati jantan.

Ketertarikan monyet ekor panjang jantan pada betina berhubungan dengan kadar estrogen. Jantan akan lebih tertarik pada betina dengan kadar estrogen yang tinggi, yang muncul selama fase fertil betina. Periode menjelang ovulasi merupakan periode saat kadar hormon estrogen betina meningkat, yang mengakibatkan meningkatnya produksi feromon, adanya copulation calls, pembengkakan area kelamin, serta berbagai perilaku lainnya (Engelhard dkk. 2005: 196).

Preferensi jantan dalam kelompok yang lebih memilih untuk kawin dengan Betina1 dibanding Betina2 diasumsikan Betina 1 memiliki kadar hormon estrogen yang lebih tinggi daripada Betina2. Selain itu, selama pengamatan, Betina2 terlihat beberapa kali menunjukkan perilaku agresif kepada jantan. Perilaku agresif Betina2 dapat merupakan penyebab ketiga jantan lebih memilih untuk kawin dengan Betina1, karena motivasi reproduktif pada jantan salah satunya dipengaruhi oleh interaksi sosial dengan betina (Engelhard dkk. 2004: 916).

\section{KESIMPULAN}

Dari penelitian ini dapat disimpulkan bahwa monyet ekor panjang jantan yang telah divasektomi masih memperlihatkan perilaku reproduksi dengan ditandai adanya interaksi yang mengarah pada perilaku reproduktif kepada betina. Akibat masih munculnya perilaku reproduksi monyet jantan, maka monyet betina memberikan respons positif dan negatif dalam berperilaku reproduktif terhadap jantan. Perilaku reproduktif positif meliputi mendekati jantan (Approaching Sex Partner), menunjukkan genitalia pada jantan (Female Present Genitals) dan perilaku reproduksi negatif menolak jantan (Female Refuses Sex). Perilaku lain yang teramati adalah perilaku agresif antarjantan dalam memperebutkan betina dan perilaku grooming betina terhadap jantan.

\section{DAFTAR PUSTAKA}

[1] J.Altmann, Observational Study of Behavior: Sampling Methods. Behaviour, vol .49, pp.227-265,1974

[2] S.Anuar, Social Organization and Mating System of Macaca fascicularis (Long Tailed Macaques), International Journal of Biology. Vol 3, No 2, pp: 23-31,2010

[3] Egbedate, A.O., E.L. Gadsby, A.Idoiga, \& P.D. Jenkins. 2014.Vasectomy in Drill Monkeys (Mandrillus leucophaeus)- A Population Management Tool. World Journal of Zoology. 9 (2): 107-110.2014

[4] A.Engelhardt, M. Heistermann, J.K. Hodges, P.Nurnberg, dan C.Niemitz, Determinants of male reproductive success in wild macaques (Macacafascicularis) male monopolisation, female mate choice or post copulatory mechanisms?, Behavioral Ecology Sociobiol, Vol 59, pp 740-752, 2006

[5] A.Engelhard, J.B. Pfeifer, M.Heistermann, C. Niemtz, J.A.R.A.M.V. Hoff, dan K.Hodges. Assesment of female reproductive status by male longtailed macaques, Macaca fascicularis, under natural conditions. Animal Behaviour. Vol 67, (7709), pp 951 - 924, 2004 
[6] Engelhardt, A., J.K. Hodges, C.Niemitz, \& M. Heistermann. 2005. Female sexual behavior, but not sex skin swelling, reliably indicates the timing of thefertile phase in wild long -tailed macaques (Macaca fascicularis). Hormones andBehavior, Vol 47, pp 195-204, 2005

[7] M.D. Gumert, Payment for sex in macaque mating market. Animal Behavior. Vol 74, No 6, pp 1655-1667, 2007

[8] Gumert, M.D. 2015. Reciprocity in a Wild Group of Long-Tailed Macaques (Macaca fascicularis) at Tanjung Putting National Park, Kalimantan Tengah, Indonesia: An Analysis of Social Currency Exchange [Thesis]. Singapore: Nanyang Technological University. IAR Indonesia. 2010. Indonesia volunteer guide. http//www.internationalanimalres cue.org/indonesiavolunteerguidehtml,

[Diakses 2 September 2016 pukul 9.13 WIB]

[9] IUCN. 2016. The IUCN Red List of Threatened $\quad$ Species. 1 hlm. http://www.iucnredlist.org/details/1 2551/0, [Diakses 1 September 2016, pk. $16.40 \mathrm{WIB}]$

[10] N.J.Kemp, dan J.B. Burnett. Kera Ekor Panjang (Macacafascicularis) di Pulau Nugini: Penilaian dan Penatalaksanaan Resiko

Terhadap
KeanekaragamanHayati [Laporan]. Washington, DC: Indo-Pacific Conservation Alliance. 2003

[11] Noordwijk, M.A., \& C.P.V. Schaik, The Effects of Dominance Rank and Group Size on Female Lifetime Reproductive Success inWild Long-Tailed Macaques, Macaca fascicularis.Primates, Vol 40, No 1, pp 105-130, 1999

[12] Peng, B., R.D. Zhang, X.S. Dai, X.Z.Deng, Y. Wan, \& Z.M. Yang, Quantitative (stereological) Study of The Effects of Vasectomy on Spermatogenesis in Rhesus Monkeys (Macaca mulatta). Reproduction. Vol 124, pp 847-856. 2002

[13] Phoenix, C.H, Effects of Dihydrotestosterone on Sexual Behavior of Castrated Male Rhesus Monkeys. Physiology and Behavior. Vol 12, pp 1045-1055, 1973

[14] Saputa, A., Marjono, D. Puspita, \& Suwarno, Studi Perilaku Monyet Ekor Panjang (Macaca fascicularis) Di Taman Wisata Alam Grojogan Sewu Kabupaten Karanganyar. Bioeksperimen. Vol 1, No 1, pp 6-11, 2015

[15] Thomsen, Ruth, Sperm Competition and The Function of Masturbation in Japanese Macaques (Macaca fuscata) [Disertasi]. Munchen: Universitat Munchen, 2000 